\title{
DESIGNING A MORE INCLUSIVE WORLD
}

\author{
Sam Waller \\ Pat Langdon \\ John Clarkson \\ University of Cambridge, Engineering Design Centre, UK \\ Contact details: sdw32@cam.ac.uk
}

\begin{abstract}
This paper summarises the what, why and how of inclusive design, and presents key contributions of the 2006-2010 i design research consortium, the third successive research consortium funded by the Engineering and Physical Sciences Research Council as part of the Extending Quality of Life initiative. Throughout 10 years of i design research, the overarching goals have been to provide industrial decision makers with mechanisms for understanding the significance of age- and capabilityrelated factors, and to provide the design community with the techniques and guidance required to deliver better products and services for people of all ages and abilities. In this latest period of research, the specific emphasis has been on quantifying design exclusion and enabling designers to work with users.
\end{abstract}

KEY WORDS inclusive design; user-centred; calculating exclusion

\section{INTRODUCTION}

The institutions with the i design research consortium are the University of Cambridge Engineering Design Centre, Royal College of Art Helen Hamlyn Centre, University of Cambridge Well-being Institute, and Loughborough University Ergonomics and Safety Research Institute (Box 1). When introducing inclusive design, it is critical to communicate what it is, why it is worthwhile and how to do it. First, though, it is usually necessary to challenge the stereotypical assumption of 'mainstream products' for ‘fully able' users and 'assistive technology' for 'disabled users'. In fact, advances in assistive technologies can offer benefits to the wider population; for example, predictive text was first developed for disabled people who could not use a standard computer keyboard (Newall, 2003; Arnott \& Javed, 1990). Furthermore, better designed mainstream products could reduce the need for everyday assistive aids (Keates \& Clarkson, 2003). For instance, rather than providing an ugly 
and stigmatising strap-on telephone amplifier, why not design mainstream telephones with builtin volume amplification?

Indeed, the recently launched BT freestyle phone has volume amplification, and its mainstream styling and mass-market appeal keep its price down. Understanding population diversity is the foundation of inclusive design (Clarkson et al, 2007), and the BT Freestyle is one of the first products to emerge from a revised development process where improved knowledge of this diversity was used to inform design decisions. Important aspects of population diversity include lifestyle, aspirations, ability levels, gender, ageing and past experiences.

Inclusive design informs business decisions according to the diverse needs of users in realworld contexts, and thereby enables products to reach wider markets, improves customer satisfaction and reduces the costs associated with customer support and returns. To achieve this, tools and processes are needed to enable sufficient exploration of the user and business needs, and to support evaluation against those needs. The i design consortium's contributions to the design of a more inclusive world are now outlined. These include improving the understanding of capability variation, enabling designers to better understand users, and quantifying design exclusion.

\section{UNDERSTANDING CAPABILITY VARIATION}

Key improvements in understanding capability variation include recognising that:

- capability variation is a continuum that we are all on, at all stages of our lives

- real-world contexts can significantly affect a person's capability

- disability rarely involves a single type of severe loss.

Ability loss is evident throughout the population at varying levels of severity. Ability varies with age, yet a diverse range of abilities is also evident at any particular age, and this diversity is exacerbated by different real-world contexts. Important aspects of the environmental context include ambient lighting, background noise, vibration, motion and temperature (Elton \& Nicole, 2010). In particular, older adults need letters to be $1.9 \mathrm{~mm}$ bigger in order to read them under street lighting compared to reading in daylight, and UK winter temperatures $\left(5^{\circ} \mathrm{C}\right)$ significantly affect dexterity performance (Elton \& Nicole, 2009; Elton et al, 2010). Such variations need to be accounted for in 
the design of everyday products to ensure they are usable in everyday environments. Further research has specifically examined the co-occurrence of ability loss. This is possible from the 1996/97 Disability Follow-up Survey (DFS) (Grundy et al, 1999), which is the most recent publicly available UK dataset covering all the types of ability loss relevant to performing everyday tasks (Johnson et al, 2009).

The DFS questions were grouped together in 13 different ability categories, seven of which are particularly relevant for inclusive design. Further re-analysis (Waller et al., 2010a) of the survey data (DSS, Social Research Branch, 2000) has combined the relevant questions into five categories, which are named vision, hearing, thinking, arms \& hands, and locomotion.

Benktzon (1993) used a segmented pyramid to represent increasing levels of capability loss, and combining this visualisation method with the pre-analysed survey data has led to a groundbreaking tool for communicating co-occurrence, shown in Figure 1.

This segmented pyramid shows a breakdown of the UK adults with moderate or severe ability loss, as defined in Figure 1. Each segment further shows how many people have a single ability loss, and how many have multiple ability losses

Depicting the survey data in this manner reveals the groundbreaking insight that: Of the people with some kind of severe ability loss, $83 \%$ of them also have another kind of ability loss.

In stark contrast to this insight, legislation to protect the rights of those with disabilities typically considers only single, separate types of ability loss. Similarly, many assistive technology devices are designed to accommodate a particular kind of severe ability loss, but typically assume that the user is otherwise fully able.

Population statistics provide a general understanding of diversity, yet the delivery of more inclusive products also requires understanding of the specific impact of design decisions on particular types of real users: the next section examines the i design consortium's contribution to enabling designers to better understand users. 


\section{ENABLING DESIGNERS TO UNDERSTAND USERS}

Inclusive design depends on resources that can help the design team understand user diversity, which can be through representative user methods and direct involvement with real users. Working with people is the highest-fidelity approach to understanding real-world needs, but is inevitably specific to the sample of users involved. In contrast, representative user methods can depict a broader range of issues prevalent across the customer base, but with reduced fidelity. Each approach has strengths and weaknesses, so they are best used to complement each other. Representative user methods include market segmentation, personas (character descriptions of key users) and impairment simulation. Many companies have an existing segmentation model for their customers, and have developed specific product offerings to satisfy the diverse needs of these segments. However, design teams do not always understand the lifestyles, aspirations, social circumstances and ability losses of the people in the different market segments. A set of personas can help to capture these aspects of customer diversity, and therefore better support informed decision-making (Pruitt \& Adlin, 2006). Personas are especially powerful because of their flexibility. User research can ensure that the set of personas best reflects the true diversity evident in different market segments, and across the whole customer base. However, personas can still deliver immediate value when they are of lower fidelity, and they are readily understood by all the stakeholders in the development process. Personas can be used to explore user needs, inspire creativity and help evaluate designs from the perspective of the users. As an alternative method of representing users, impairment simulation can provide an interactive and exciting way to:

- understand how ability loss affects real-world tasks

- experience the frustration and difficulty that may be associated with capability loss

- evaluate alternative products with simulated ability loss.

Impairment simulators may be wearable or software-based, and a freely available softwarebased impairment simulator is available online (www.inclusivedesigntoolkit.com). The cost, speed and ease of access mean that these simulators can be used early and repeatedly throughout the design process, yet no simulation can ever truly model what it is like to live with a particular capability reduction on an everyday basis. In order to complement the use of representative user methods, user involvement may involve direct user contact such as interviews, or 
indirect contact such as questionnaires. It may involve open-ended exploration, such as a cultural probe, or be very structured towards specific tests, such as user trials. The activities may be conducted in real-world contexts, such as participant observation, or in controlled conditions, such as focus groups. The objective might be to obtain users' feedback on particular ideas, or to work with users to generate ideas. The i design consortium has produced a web-based resource (www.designingwithpeople.org) containing further information on these various ways of working with and representing users, together with ethical guidance and practical resources to help carry out user involvement. Once it is understood what individual users can and cannot do with a product, these insights become particularly powerful when quantified according to the proportion of a national population who would have similar issues.

\section{QUANTIFYING DESIGN EXCLUSION}

Exclusion occurs when the demands of operating a product exceed the capability of the user, given the environmental context (Persad et al, 2007). For example, consider a user with mild longsightedness who cannot read the text labels on the back of a television because the text lacks sufficient contrast and the ambient lighting is poor. Inclusive design aims to minimise preventable design exclusion for mainstream products, especially with respect to for those with minor ability loss. In this context, a mainstream product is one that is readily available off the shelf in competitive markets, and produced according to economies of scale. Design decisions for commercially competitive mainstream products must typically be justified according to the number of customers who will benefit, which requires a population-based method for quantifying exclusion.

Predicting the number of people who are unable to perform a particular task with a particular product in a particular real-world context requires a single nationally representative dataset that contains generic measures with the required predictive power, linked together with a task and context assessment model that can predict user performance. These generic measures need to be predictive of user performance for product interaction cycles that include perceiving, thinking and acting in real-world contexts. While there are many existing datasets and precise models for particular 
parts of this interaction cycle, none of them are holistic and detailed enough to predict the entire cycle (Johnson et al., 2009).

The primary objective of the 2006-2010 i design program is to investigate how to fulfil this need. The research activities include:

- Developing an exclusion audit procedure and design tool based on the best currently available survey data, and testing its reliability and validity

- Investigating the best possible survey measures and predictive models for everyday product use in the real world, in preparation for a new survey

- Combining the insights from these activities to produce an exclusion audit design tool that links together the new survey data with a corresponding audit procedure and predictive model

The DFS is the best currently available dataset for predicting UK design exclusion (Johnson et al., 2009). A standard operating procedure for using this data was therefore developed, which involves:

- specifying assumptions, including the goal that the user is trying to achieve, the initial state of the product and other relevant items, and the environment in which the interaction takes place

- breaking down the goal into the steps that the user completes

- examining each step and describing the demands placed on the user's sensory, cognitive and motor abilities

- using the assessors judgement to map these demands to the DFS data

- calculating how many people will be excluded.

The reliability and validity of this standard operating procedure critically depends on the consistency with which assessors can use their judgement to map product demands to the DFS data. An initial experiment therefore investigated how the number of data points presented to untrained assessors affected the consistency of these judgements.

The results suggested that four anchor-point scales were more suitable than two anchor-point scales, but participants found the original scales difficult to use, as they 
confounded many different aspects of ability loss (Waller et al, 2009). For example, a single scale contained data regarding ability losses related to 'fine finger manipulation' and 'picking up and carrying'. Subsequently, further re-analysis of the data separated out these different aspects of ability loss (Waller et al, 2010b), which enabled a second experiment to explore the use of a flowchartbased assessment method and simplified scales. Although not yet published, the initial findings suggest that assessment consistency was improved. The simplified scales are now included in the i design consortium's freely available exclusion calculator (www.inclusivedesigntoolkit. com). Investigating the best possible survey measures that can predict people's ability to use everyday products in the real world has involved planning and conducting a 100-person study to examine the relative predictive power of standard performance measures, compared with different styles of self-reported questions including:

- how easy or difficult do you find it to...

- how often do you...

- how often do you have difficulty doing...

- have you changed the way that you...

The results have informed the design of a 400-person national survey. This survey will include a mixture of self-report and performance tests, the results of which will enable the prediction of the proportion of survey participants who would be unable to perform a particular task with a particular real-world product.. The results of the 400 person survey containing these measures will be available by the end of 2010, in preparation for a subsequent nationally representative survey. These survey results will provide a unique opportunity for business decision makers to help quantify the effects of design decisions.

\section{CONCLUSION}

This paper has summarised the i design research consortium's contribution to enabling the design of a more inclusive world, which has included understanding capability variation, enabling designers to understand users and quantifying design exclusion. An enhanced understanding of capability variation now places cooccurring ability loss as the most common type of ability loss. Methods for 
calculating exclusion have to take account of co-occurrence, and have so far had to rely on the best available data set that covers the different types and levels of ability loss relevant for interacting with everyday products. The research program will culminate with the results of a 400-person pilot survey designed specifically for calculating exclusion, together with tools and techniques to use this survey data in practice. Finally, the recommended approach is to use population data and usercentred methods to complement each other.

\section{REFERENCES}

Arnott JL \& Javed MY (1990) Small text corpora in character disambiguation for reduced typing keyboards. Proceedings of RESNA 13. Washington, DC. Benktzon M (1993) Designing for our future selves: the Swedish experience. Applied Ergonomics 24 (1) Special Issue: Designing for our future selves 19-27.

Clarkson PJ, Coleman R, Hosking I \& Waller S (2007) Inclusive Design Toolkit. EDC, Cambridge, UK. www. inclusivedesigntoolkit.com.

Johnson D, Clarkson PJ \& Huppert F (2009) Capability measurement for inclusive design. Journal of Engineering Design 21 (2/3) 275-88.

Department of Social Security Social Research Branch (2000) Disability Follow-up to the 1996/97 Family Resources Survey [computer file]. Colchester, Essex: UK Data Archive [distributor], SN: 4090. The complete set of questions are available at www.data-archive.ac.uk/doc/4090\mrdoc $\backslash$ pdf14090userguide.pdf.

Newall A (2003) The future for ICT. In: PJ Clarkson, R Coleman, S Keates \& C Lebbon (Eds) Inclusive Design: Design for the whole population. London: Springer. Persad U, Langdon PM \& Clarkson P (2007) Characterising user capabilities to support inclusive design evaluation. Universal Access in the Information Society (UAIS) 6 (2).

Elton E, Dumolo D \& Nicole C (2010) Have I just pressed something? The effects of everyday cold temperatures on dexterity. In: PM Langdon, PJ, Clarkson \& P Robinson (Eds) Designing Inclusive Interactions. London: Springer. 
Pruitt J \& Adlin T (2006) The Persona Lifecycle: Keeping users in mind throughout the design process. San Francisco: MorganKaufmann.

Elton E \& Nicole C (2009) Now you see it, now you don't. Proceedings of Include 2009 Conference. London: Royal College of Art, Helen Hamlyn Centre.

Waller SD, Goodman-Deane J, Langdon PM, Johnson D \& Clarkson PJ (2009) Developing a method for assessing product inclusivity. Proceedings of the 17th International Conference on Engineering Design. Stanford, USA.

Elton E \& Nicole C (2010) The importance of context in inclusive design. In: M Anderson (Ed) Proceedings of the Contemporary Ergonomics Conference. Keele. Keates S \& Clarkson PJ (2003) Countering Design Exclusion: An introduction to inclusive design. London: Springer. Grundy E, Ahlburg D, Ali M, Breeze E \& Sloggett A (1999) Research Report 94: Disability in Great Britain. London: Corporate Document Services.

Waller SD, Williams EY, Langdon PM \& Clarkson PJ (2010a) Understanding the cooccurrence of ability loss. In: PM Langdon, PJ Clarkson \& P Robinson (Eds) Designing Inclusive Interactions. London: Springer. Waller SD, Williams EY, Langdon PM \& Clarkson PJ (2010b) Quantifying exclusion for tasks related to product interaction. In: PM Langdon, PJ Clarkson \& P Robinson (Eds) Designing Inclusive Interactions. London: Springer. 
Figure 1: A SEGMENTED MODEL OF ABILITY LOSS

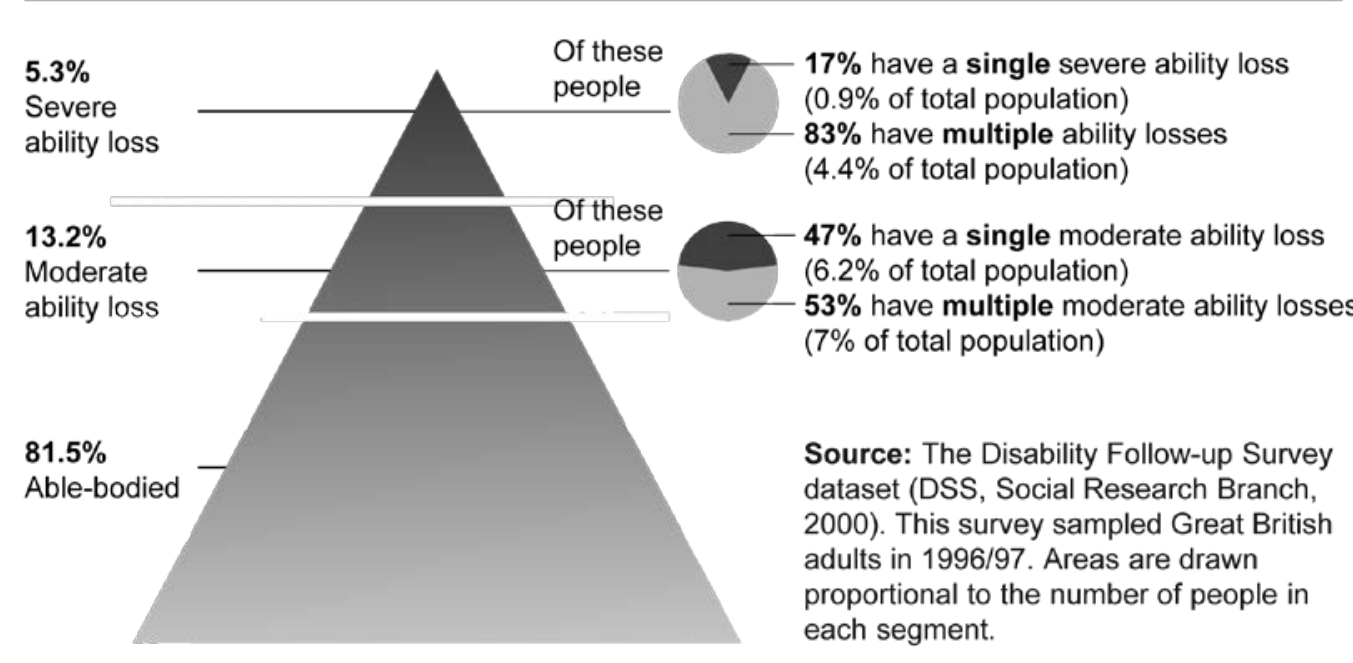

A person with severe ability loss has one or more of the following types of losses:

- Vision: Cannot see well enough to recognise a friend who is at arms length away

- Hearing: Cannot follow a TV programme with the volume turned up

- Thinking: Cannot count well enough to handle money and/or Often gets confused about what time of day it is and/or Often forgets the names of friends and family that are seen regularly

- Reach \& dexterity: Cannot pick up and hold a mug of tea or coffee with either hand

- Mobility: Cannot walk up and down one step

A person with moderate ability loss has one or more of the following types of losses:

- Vision: Has difficulty reading ordinary newsprint and/or Has difficulty recognising a friend across the road

- Hearing: Has difficulty following a conversation against background noise

- Thinking: Thoughts tend to be muddled or slow and/or Often forgets what was supposed to be doing in the middle of something and/or Often loses track of what is being said in the middle of a conversation and/or Cannot remember a message and pass it on correctly and/or Has difficulty expressing themselves to other people and/or Has difficulty understanding other people and/or Often forgets to turn things off such as fires, cookers or taps

- Reach \& dexterity: Has difficulty tying a bow in laces and/or Cannot pick up and carry a bag of potatoes with each hand and/or Has difficulty raising both arms above the head

- Mobility: Cannot walk 350 m without stopping and/or Cannot manage a flight of 12 steps, even if a handrail is available and/or Occasionally needs to hold on to something to keep balance

Notes: Prevalence statistics are calculated based on 43.3 million GB adults living in private households (Grundy et al., 1999). This represents a refined assumption compared to previous publications by the same authors, which calculated prevalence statistics based on 45.6 million adults living in the whole of Great Britain. The survey questions used to define the pyramid's boundaries were only chosen if the authors judged they best reflected their corresponding type of ability loss, and none of the other four types of ability loss. 